\title{
Produtos Educacionais para o Ensino, a Aprendizagem e a Formação em Educação Matemática: contribuições do PPG Educação Matemática UFJF
}

\author{
Fernanda Angelo Pereira \\ Mestre em Educação Matemática \\ Escola Municipal Coronel Ribeiro dos Reis, Pirapetinga, MG, Brasil \\ fernandap@id.uff.br
}

\section{Chang Kuo Rodrigues}

Doutora em Educação Matemática

Universidade Federal de Juiz de Fora, MG, Brasil

changkuockr@gmail.com

\author{
Maria Cristina Araújo de Oliveira \\ Doutora em Educação \\ Universidade Federal de Juiz de Fora, MG, Brasil \\ cristina.oliveira@ice.ufjf.br
}

\section{Resumo}

Este artigo tem como objetivo apresentar uma caracterização dos Produtos Educacionais produzidos pelo PPG em Educação Matemática (PPGEM) da Universidade Federal de Juiz de Fora (UFJF) ao longo de seus 10 anos de existência. Dada a vinculação dos Produtos às Dissertações ambos foram objeto de análise. O trabalho de análise das Dissertações para identificar focos e subfocos tomou como referência inicial estudos anteriores de Fiorentini que categorizavam as temáticas de investigação em Educação Matemática. Contudo, precisaram ser adaptados e ampliados, pois com uma diferença temporal de quase 20 anos, novas problemáticas de pesquisa foram constituídas. Assim, emergiram novos focos e subfocos dada a diversidade temática observada nessas produções. A análise permitiu identificar a convergência das Dissertações e Produtos Educacionais com as linhas de pesquisa consideradas no Programa, bem como a prevalência de três temáticas de investigação: Educação Financeira, História da Educação Matemática e Tecnologias da Informação e Comunicação na Educação Matemática. De acordo com os resultados do mapeamento dos Produtos Educacionais, foi constatado que a predominância é de trabalhos com foco nos mesmos temas das dissertações, além de uma quantidade significativa que trata de temas relacionados à Geometria. Foi observado também que grande parte dos Produtos é apresentada na forma de atividades e tarefas, igualmente destinada a professores e alunos.

Palavras-Chave: Educação Matemática, Mestrado Profissional, Produto Educacional, Tendência Temática, PPGEM. 


\title{
Educational Products for Teaching, Learning and Training in Mathematics Education: contributions of Postgraduate Program in Mathematics Education UFJF
}

\begin{abstract}
This article aims to present a characterization of the Educational Products produced by PP in Mathematics Education (PPGEM) of the Federal University of Juiz de Fora (UFJF) over its 10 years of existence. Given the link between the Products and the Dissertations, both were analyzed. The analysis work of the Dissertations to identify focuses and subfocuses took as an initial reference previous studies by Fiorentini that categorized the research topics in Mathematics Education. However, they needed to be adapted and expanded, since with a time difference of almost 20 years, new research problems were created. Thus, new focuses and subfocuses emerged, given the thematic diversity observed in these productions. The analysis made it possible to identify the convergence of Dissertations and Educational Products with the lines of research considered in the Program, as well as the prevalence of three research themes: Financial Education, History of Mathematics Education and Information and Communication Technologies in Mathematics Education. According to the results of the mapping of Educational Products, it was found that the predominance is of works focused on the same themes as the dissertations, in addition to a significant amount that deals with themes related to Geometry. It was also observed that most of the Products are presented in the form of activities and tasks, also intended for teachers and students.
\end{abstract}

Key-words: Mathematics Education, Professional Master's, Educational Product, Thematic Trend, PPGEM.

\section{Considerações Iniciais}

A atuação do professor de matemática, ou ainda do professor que ensina matemática, nos diferentes níveis educativos se constitui cada vez mais num desafio. Entre tantas mudanças, demandas, contextos profissionais e educacionais, o trabalho em sala de aula, no ofício de ensinar e possibilitar aprendizagens em matemática é a frente mais importante em que esse profissional tem que desempenhar o seu papel.

Em grande medida os Programas de Pós-Graduação (PPG), particularmente os profissionais, da área de Ensino da Capes têm sido cobrados no sentido de impactarem o sistema educacional em "termos de avanço do conhecimento científico e tecnológico na área, bem como nas repercussões das investigações na qualidade do ensino brasileiro" (CAPES, 2019, p.10).

O campo da Educação Matemática tem por natureza estreita relação com esse cenário na medida em que as pesquisas desenvolvidas envolvem, entre outros aspectos, os contextos educacionais relativamente ao conhecimento matemático, aos processos de ensino e de aprendizagem, a formação dos professores, a utilização de tecnologias digitais, etc.

Revista de investigação e divulgação em Educação Matemática, Juiz de Fora, v. 4, n. 1, p. 1-25, jan./dez. 2020. 
Este artigo tem como objetivo apresentar uma caracterização dos produtos educacionais produzidos pelo PPG em Educação Matemática (PPGEM) da Universidade Federal de Juiz de Fora (UFJF) ao longo de seus 10 anos de existência.

\section{O Programa de Pós-Graduação em Educação Matemática da Universidade Federal de Juiz de Fora}

O Mestrado Profissional em Educação Matemática do Programa de Pós-Graduação em Educação Matemática da Universidade Federal de Juiz de Fora (PPGEM) foi aprovado pela Coordenação de Aperfeiçoamento de Pessoal de Nível Superior (CAPES) em agosto de 2008, no âmbito da área de Ensino, e em março de 2009 iniciou suas atividades regulares. Caracterizado como um programa de pós-graduação stricto sensu, o curso tem o objetivo de operar, a partir da pesquisa em Educação Matemática, na formação continuada de professores que ensinam Matemática para o pleno exercício da docência na Educação Básica ou Superior.

A Educação Matemática numa conceituação formulada no princípio da construção desse campo do conhecimento no Brasil, a partir da década de 1980, foi assim definida por Carvalho (1991, p. 18): "o estudo de todos os fatores que influem, direta ou indiretamente, sobre todos os processos de ensino-aprendizagem em Matemática e a atuação sobre estes fatores". Obviamente tal formulação de caráter bastante abrangente mantém uma certa atualidade sem, contudo, explicitar a ampliação e o aprofundamento do campo tanto em nível de investigação quanto profissional, ligado às práticas docentes, à elaboração de documentos oficiais, entre outros espaços de atuação.

A atuação do PPGEM se baliza desde o início no paradigma sistematizado em D’Ambrósio (1996) sobre a conceituação da pesquisa em Educação Matemática como possibilidade de articulação entre teoria e prática. Assim, o Programa tem como objetivo atuar formando professores que ensinam matemática na Educação Básica e Superior para que utilizem a pesquisa em suas práticas profissionais.

Nesse campo do conhecimento também estão envolvidos os processos de ensino e aprendizagem da matemática e os embasamentos filosóficos, históricos, cognitivos e científicos. A pesquisa no Programa também se preocupa e incentiva a integração de novas tecnologias no contexto da educação matemática, no estudo de metodologias referenciadas teoricamente, que influenciam diretamente a prática docente e a construção do conhecimento.

Nesses termos, há duas linhas de pesquisa que abarcam as investigações produzidas no 
Programa, a saber: a primeira, Ensino e Aprendizagem da Matemática, Análise dos condicionantes da sala de aula e Intervenção Pedagógica em Matemática e, a segunda, Tecnologias da Informação e Comunicação na Educação Matemática. A primeira linha se pauta nos condicionantes teóricos e metodológicos que respaldam os questionamentos em torno das práticas pedagógicas, ensino e aprendizagem de Matemática, em todos os níveis de ensino, com destaque para a Educação Básica, com propostas consolidadas para serem efetivamente implementadas.

Por outro lado, a segunda linha segue ancorando as pesquisas em que prevalece o meio, a tecnologia, em prol do processo de ensino e de aprendizagem nos diferentes níveis de ensino, nesse sentido, portanto, concatenada com os avanços tecnológicos tão presentes nos dias de hoje.

A composição do corpo docente do PPGEM foi a referência para o delineamento das duas linhas de pesquisa. O grupo inicial reunia dez professores doutores em Educação Matemática de formação, doutores em Matemática, em Educação e em Ciência da Computação. Essa diversidade de formação é bastante representativa da área de Ensino, conforme sustenta a investigação de Massi et al. (2020). O artigo analisa o perfil dos orientadores que atuam na área de Ensino da Capes, manifestando preocupações com as implicações da pluralidade de formação dos orientadores que atuam na área, particularmente sobre as condições de realização de seus próprios doutorados em termos de bolsas, idade de finalização do curso, produção acadêmica entre outros aspectos. Em suma os autores questionam "as disparidades de condições socioformativas dos orientadores e como elas impactam na sua atuação e, consequentemente, na avaliação dos Programas de Pós-Graduação" (MASSI; CARVALHO; GIORDAN, 2020, p. 429). Nas conclusões do texto, os autores também anunciam a necessidade de novos estudos para tratar o que consideram uma disparidade entre os mestrados profissionais e acadêmicos da área.

O que intencionamos mostrar é que o trabalho em torno da formação em um Mestrado Profissional em Educação Matemática, desde 2009, possibilitou constituir um corpo docente estável, que pesquisa e orienta no campo da Educação Matemática, embora essa área não tenha sido a de formação inicial de todos os seus membros. Tal consideração será melhor explorada a partir da análise das dissertações e produtos defendidos no âmbito do PPGEM.

No processo de constituição do corpo docente do PPGEM e da própria trajetória de consolidação do Programa cabe destacar a importância do projeto de Reestruturação e Expansão 
das Universidades Federais (REUNI), publicado pelo Decreto n ${ }^{\circ} 6.096$ em 2007, através do qual, em 2009, logo após a implementação da primeira turma do PPGEM, dois outros professores com doutorado em Educação Matemática vieram a integrar o corpo docente.

A parceria com a Ciência da Computação, na sua dimensão para o ensino e a aprendizagem de Matemática, foi consolidada com vinda de três outros professores em substituição a dois que atuaram inicialmente.

Em 2014, o grupo praticamente alcançou sua formação atual com o credenciamento de dois professores com doutorado em Educação Matemática, um professor com doutorado em Educação e um em Estatística. Posteriormente ingressou no corpo docente um outro professor doutor em Estatística. Mais recentemente, em 2018, um professor com doutorado em Educação Matemática e egresso da primeira turma de 2009 do PPGEM, ingressou no Programa.

Cabe destacar ao menos duas parcerias internacionais importantes nessa trajetória; a primeira com o professor José Manuel Matos aposentado pela Universidade Nova de Lisboa, que é visitante por um período de dois anos, com financiamento institucional via edital da PróReitoria de Pós-Graduação (PROPP) da UFJF. A pesquisa desenvolvida por professores do corpo docente em parceria com o professor ocorre desde 2010, quando esteve pela primeira vez na UFJF, participando de um Seminário de História da Educação Matemática.

A segunda parceria é com o professor Arthur Powell da Rutgers University, que já atuou diversas vezes em cursos de verão e inverno. Recentemente o professor atuou no Global July, que é um programa de internacionalização desenvolvido pela UFJF desde 2017, que oferece a estudantes de graduação e pós-graduação cursos dados por especialistas em suas respectivas línguas maternas, relacionados às formações específicas. O professor Arthur ministrou um curso sobre tendências metodológicas de pesquisa em Educação Matemática em julho/agosto de 2019. Com esse percurso delineado chega-se à composição atual do corpo docente.

O PPGEM também conta com a publicação da Revista de Investigação e Divulgação em Educação Matemática - RIDEMA - que foi criada no ano de 2017. A revista visa divulgar pesquisas científicas em andamento ou concluídas na área da Educação Matemática. Com isso, a troca de informações acontece entre estudantes, professores e pesquisadores a fim de promover o desenvolvimento desse campo investigativo. 


\section{Tendências Temáticas das Dissertações}

Embora o foco do presente artigo seja caracterizar os produtos educacionais produzidos no PPGEM ao longo de seus dez anos de existência, dada a vinculação dos produtos às dissertações, faz-se necessária a análise preliminar das mesmas. Considerando o paradigma da articulação da teoria com a prática via pesquisa (D’AMBROSIO, 1996), adotou-se a indissociabilidade entre dissertação e produto educacional para a construção do mesmo. $\mathrm{Ou}$ seja, o produto é elaborado conjuntamente com a construção do projeto de pesquisa que resulta na dissertação de mestrado. Essa perspectiva de trabalho parece contradizer a possível disparidade anunciada por Massi et al. (2020).

Desde o início de suas atividades, foram 123 dissertações defendidas entre 2011 e 2019 no PPGEM. Como forma de caracterizar as investigações que foram feitas ao longo desses 10 anos de pesquisa, decidiu-se fazer um levantamento das temáticas das Dissertações e Produtos Educacionais (PE) apresentados no Programa. À princípio tomou-se como referência aquelas temáticas já identificadas por Fiorentini (2002), que apresenta os principais focos de pesquisa da Educação Matemática entre 1998 e 2001, destacando as origens e autorias dos trabalhos, reunindo as pesquisas em grupos temáticos, ressaltando as principais referências de cada tema.

Contudo, os focos temáticos identificados em Fiorentini (2002) não abrangem a diversidade de objetos de pesquisa observados no levantamento dos temas das dissertações do PPGEM. Por ter sido publicado há quase 20 anos, as temáticas em Fiorentini (2002) precisaram ser adaptadas para essa análise, depois de tanto tempo, surgiram novas áreas e subáreas de pesquisa que ao longo dos anos foram se estruturando e fazendo parte da discussão no meio acadêmico. Assim, foram criados novos focos temáticos, outros não foram usados e alguns adaptados. O mesmo aconteceu na construção dos subfocos temáticos.

A metodologia aplicada para a identificação dos temas de pesquisa predominantes no PPGEM, além de fornecer informações específicas das dissertações por meio do fichamento, que é descrito em seguida, foca no processo de levantamento da quantidade de trabalhos publicados de acordo com a linha de pesquisa de cada orientador, os focos e subfocos temáticos de mais frequência e as palavras-chave que mais se destacaram. Todas as informações obtidas foram distribuídas em planilhas, organizadas por ano. Ao longo deste trabalho, são apresentados quadros resumindo essas informações, bem como dados importantes constatados a partir da análise do levantamento executado. 
Com isso, a primeira etapa executada foi o levantamento da quantidade de dissertações defendidas por ano entre 2009 e 2019. No Quadro 1 é possível perceber a variação de trabalhos apresentados ao longo desse período.

Quadro 1 - Quantitativo de Dissertações defendidas entre 2009 e 2019 no PPGEM

\begin{tabular}{|c|c|}
\hline Ano & $\mathbf{N}^{\mathbf{0}}$ de Dissertações defendidas \\
\hline 2009 & 0 \\
\hline 2010 & 0 \\
\hline 2011 & 13 \\
\hline 2012 & 11 \\
\hline 2013 & 18 \\
\hline 2014 & 9 \\
\hline 2015 & 16 \\
\hline 2016 & 12 \\
\hline 2017 & 18 \\
\hline 2018 & 15 \\
\hline 2019 & 11 \\
\hline Total & 123 \\
\hline
\end{tabular}

Fonte: sítio do PPGEM.

No Quadro 1 consta que nos anos de 2009 e 2010 não houve nenhuma defesa, isso se deve ao fato de que a primeira turma que ingressou no Programa em 2009, teve no mínimo 12 meses e no máximo 24 meses para concluir o curso (sem uma extensão de prazo), assim as primeiras pesquisas foram apresentadas só no ano de 2011. O número variável de defesas de cada ano é influenciado pelo número de estudantes aprovados no processo seletivo de acordo com o número de vagas abertas por cada orientador do Programa e também por extensões de prazos concedidas a alguns alunos. Por exemplo, em 2015 houve a matrícula de 20 alunos e em 2017 foram apresentados 18 trabalhos, já em 2016 foram matriculados 13 alunos e foram apresentados 15 trabalhos em 2018.

Nesta seção, o foco é nas temáticas das dissertações, pois o PE é um resultado da 
pesquisa apresentada na dissertação, ou um recurso utilizado durante a pesquisa, ou assume uma forma com características próprias, mas vinculadas ao desenvolvimento da pesquisa.

A partir dos quantitativos apresentados no Quadro 1, foi realizado um fichamento de cada uma das dissertações coletando informações gerais (ano, autor, título do trabalho, orientador/coorientador) e específicas tais como: linha de pesquisa, foco temático, subfoco temático, palavras-chave e problema ou objetivo de estudo. Todos esses dados foram organizados em planilhas eletrônicas. Para se obter as informações do fichamento foram analisados primeiramente os resumos de cada trabalho, mas como nem todos traziam com clareza essas informações, a análise se estendeu em muitos casos ao texto completo do trabalho.

O quadro a seguir mostra um resumo dos trabalhos divididos por linha de pesquisa.

Quadro 2 - Resumo dos trabalhos do PPGEM por linha de pesquisa.

\begin{tabular}{|c|c|c|c|c|c|c|c|c|c|c|c|c|}
\hline & $\mathbf{2 0 0 9}$ & $\mathbf{2 0 1 0}$ & $\mathbf{2 0 1 1}$ & $\mathbf{2 0 1 2}$ & $\mathbf{2 0 1 3}$ & $\mathbf{2 0 1 4}$ & $\mathbf{2 0 1 5}$ & $\mathbf{2 0 1 6}$ & $\mathbf{2 0 1 7}$ & $\mathbf{2 0 1 8}$ & $\mathbf{2 0 1 9}$ & Total \\
\hline $\begin{array}{c}\text { Linha de } \\
\text { Pesq. 1 }\end{array}$ & 0 & 0 & 12 & 9 & 18 & 7 & 14 & 9 & 14 & 11 & 8 & 102 \\
\hline $\begin{array}{c}\text { Linha de } \\
\text { Pesq. 2 }\end{array}$ & 0 & 0 & 1 & 2 & 0 & 2 & 2 & 3 & 4 & 4 & 3 & 21 \\
\hline
\end{tabular}

Fonte: dados da pesquisa.

Por meio do Quadro 2 pode-se observar que a linha de pesquisa 1 é predominante entre os trabalhos representando $83 \%$ das pesquisas. Isso se deve ao fato de que a maioria dos docentes do Programa (70\%) trabalham com subtemas desta linha de investigação. Essa constatação já influencia nos temas que foram identificados no processo de fichamento das dissertações. Vale ressaltar que a linha de pesquisa de cada trabalho foi identificada a partir do professor orientador.

Para ajudar na caracterização temática dos trabalhos, foi feito um resumo das 270 diferentes palavras-chave que aparecem 539 vezes, obtidas por meio do processo de fichamento. A seguir, o Quadro 3 apresenta o quantitativo das palavras-chave que apareceram mais de uma vez: 
Quadro 3 - Resumo das Palavras-chave das dissertações no período de 2009 a 2019

\begin{tabular}{|c|c|c|c|c|c|}
\hline PALAVRA-CHAVE & Quant. & PALAVRA-CHAVE & Quant. & PALAVRA-CHAVE & Quant. \\
\hline Educação Matemática & 60 & Produto Educacional & 4 & Ensino de Estatística & 2 \\
\hline $\begin{array}{l}\text { Produção de } \\
\text { Significados }\end{array}$ & 24 & Álgebra Linear & 3 & $\begin{array}{l}\text { Formação de professores } \\
\text { de Matemática }\end{array}$ & 2 \\
\hline $\begin{array}{l}\text { Educação Financeira } \\
\text { Escolar }\end{array}$ & 18 & Desenho & 3 & GeoGebra & 2 \\
\hline $\begin{array}{l}\text { História da educação } \\
\text { matemática }\end{array}$ & 14 & Educação a Distância & 3 & Geometria analítica & 2 \\
\hline Educação Financeira & 13 & $\begin{array}{l}\text { Ensino e Aprendizagem da } \\
\text { Matemática }\end{array}$ & 3 & Inflação de Preços & 2 \\
\hline Ensino Fundamental & 12 & Ensino primário & 3 & Interdisciplinaridade & 2 \\
\hline $\begin{array}{l}\text { Formação de } \\
\text { professores }\end{array}$ & 12 & Escola Nova & 3 & Legislação educacional & 2 \\
\hline Geometria & 10 & Fenomenologia & 3 & $\begin{array}{l}\text { Licenciatura em } \\
\text { Matemática } \\
\end{array}$ & 2 \\
\hline Engenharia didática & 6 & Formação de docentes & 3 & Literacia Estatística & 2 \\
\hline $\begin{array}{l}\text { Ensino e } \\
\text { Aprendizagem }\end{array}$ & 6 & Geometria Dinâmica & 3 & Metodologia & 2 \\
\hline $\begin{array}{l}\text { Tecnologias da } \\
\text { informação e } \\
\text { comunicação }\end{array}$ & 6 & Geometria Projetiva & 3 & Pesquisa-ação & 2 \\
\hline $\begin{array}{l}\text { Educação de Jovens e } \\
\text { Adultos }\end{array}$ & 5 & Matemática Financeira & 3 & Poupança & 2 \\
\hline $\begin{array}{l}\text { Educação Matemática } \\
\text { Crítica }\end{array}$ & 5 & MOOC & 3 & Produção de Tarefas & 2 \\
\hline Ensino Superior & 5 & $\begin{array}{l}\text { Pensamento matemático } \\
\text { avançado }\end{array}$ & 3 & Profissionalidade & 2 \\
\hline Matemática & 5 & Tecnologia & 3 & Revista do Ensino & 2 \\
\hline Currículo & 4 & $\begin{array}{l}\text { Teoria da transposição } \\
\text { didática }\end{array}$ & 3 & Saberes geométricos & 2 \\
\hline Curso de Serviço & 4 & $\begin{array}{l}\text { Aprendizagem colaborativa } \\
\text { apoiada por computador } \\
\text { (CSCL) }\end{array}$ & 2 & Sala de Aula Invertida & 2 \\
\hline Educação Estatística & 4 & Avaliação em Matemática & 2 & Sequência Didática & 2 \\
\hline Ensino de Matemática & 4 & Avaliação Externa & 2 & SIMAVE/Proeb & 2 \\
\hline Ensino Médio & 4 & Consumismo & 2 & Software Geogebra & 2 \\
\hline $\begin{array}{l}\text { História das } \\
\text { Disciplinas }\end{array}$ & 4 & Consumo & 2 & Tecnologias & 2 \\
\hline \multirow[t]{2}{*}{$\begin{array}{l}\text { Modelagem } \\
\text { Matemática }\end{array}$} & 4 & Desenho Geométrico & 2 & \begin{tabular}{|l|} 
Teoria Antropológica do \\
Didático
\end{tabular} & 2 \\
\hline & & & & Teoria da Atividade & 2 \\
\hline
\end{tabular}

Fonte: dados da pesquisa.

Revista de investigação e divulgação em Educação Matemática, Juiz de Fora, v. 4, n. 1, p. 1-25, jan./dez. 2020. 
Esses dados mostram uma grande dispersão das palavras-chave. Há 67 palavras-chave que ocorrem mais de uma vez e 203 que ocorrem apenas uma vez. Nas dissertações foram observadas a ocorrência de 3 a 6 palavras-chave, indicando talvez uma falta de padronização na orientação dos autores. As palavras-chave caracterizam e representam o conteúdo do trabalho, escolhidas dentro de um vocabulário controlado, além de fornecerem parâmetros de busca na web, em periódicos etc. A importância de escolher as palavras-chave que vão permitir identificar as temáticas centrais do trabalho também deve ser priorizada ao registrar uma pesquisa.

De acordo com o Quadro 3, a palavra-chave "Educação Matemática” foi identificada 60 vezes, isso quer dizer que aparece em 49\% dos trabalhos, seguida por "Produção de Significados" que aparece em $20 \%$ dos trabalhos e em terceira posição está "Educação Financeira Escolar" que foi identificada em 15\% dos trabalhos. Essas palavras que mais ocorrem, dão melhores indícios dos temas que predominaram na pesquisa realizada no PPGEM entre 2009 e 2019. As três palavras-chave, mencionadas anteriormente, que mais aparecem nos trabalhos, facilmente são relacionadas com linha de pesquisa 1 que trata do ensino e da aprendizagem da Matemática, da análise dos condicionantes da sala de aula e da intervenção pedagógica em Matemática. Inclusive, a segunda palavra-chave que teve mais frequência se refere a um subtema dentro da linha de pesquisa 1. Isso se dá também ao fato de que emergem mais pesquisas do Programa dentro dessa linha de pesquisa como mencionado anteriormente.

Após o fichamento das dissertações ser concluído, os trabalhos foram agrupados em focos temáticos e subfocos temáticos, quando possível. Os focos e subfocos emergiram dos próprios temas identificados nos trabalhos, alguns em semelhança com o que Fiorentini (2002) identificou, de acordo com o que foi esclarecido no início da seção.

A seguir, Quadro 4, é apresentado um resumo com essas informações geradas pelos fichamentos. $\mathrm{O}$ intuito é mostrar o avanço da pesquisa e a extensão teórica que a investigação no PPGEM apresenta ao longo desses 10 anos de atividade. Pode-se observar também as dimensões menos privilegiadas a fim de conhecer melhor os objetivos da pesquisa que é realizada no Programa. 
Quadro 4 - Resumo do foco e do subfoco temático das dissertações do PPGEM do período de 2009 a 2019

\begin{tabular}{|c|c|c|c|}
\hline FOCO TEMÁTICO & Quant. & SUB-FOCO & Quant. \\
\hline \multirow{8}{*}{$\begin{array}{l}\text { Estudos sobre Educação } \\
\text { Financeira }\end{array}$} & \multirow{8}{*}{25} & $\begin{array}{l}\text { Produção de significado no estudo da Matemática } \\
\text { Financeira }\end{array}$ & 14 \\
\hline & & $\begin{array}{l}\text { Educação Financeira no contexto da educação de jovens } \\
\text { e adultos }\end{array}$ & 1 \\
\hline & & $\begin{array}{l}\text { Educação Financeira sob a perspectiva da Educação } \\
\text { Matemática Crítica }\end{array}$ & 2 \\
\hline & & $\begin{array}{l}\text { estudo sobre a Educação Financeira sob a perspectiva da } \\
\text { Pedagogia Waldorf }\end{array}$ & 1 \\
\hline & & Consumismo a partir do marketing das mídias & 2 \\
\hline & & $\begin{array}{l}\text { Formação continuada de professores para a Educação } \\
\text { Financeira no Ensino Básico }\end{array}$ & 1 \\
\hline & & História da Educação Financeira Escolar & 1 \\
\hline & & $\begin{array}{l}\text { Recursos de ensino e aprendizagem para a Educação } \\
\text { Financeira }\end{array}$ & 3 \\
\hline \multirow{13}{*}{$\begin{array}{l}\text { Estudos das TIC na } \\
\text { Educação Matemática }\end{array}$} & \multirow{13}{*}{18} & Sala de aula invertida como metodologia de ensino & 1 \\
\hline & & $\begin{array}{l}\text { Mapeamento do uso de recursos educacionais digitais no } \\
\text { Ensino de Matemática }\end{array}$ & 1 \\
\hline & & \begin{tabular}{|l|} 
Recursos educacionais digitais para a Educação \\
Financeira
\end{tabular} & 3 \\
\hline & & $\begin{array}{l}\text { Recursos educacionais digitais para a formação } \\
\text { continuada de professores }\end{array}$ & 2 \\
\hline & & $\begin{array}{l}\text { Recursos educacionais digitais para o Ensino de } \\
\text { Matemática }\end{array}$ & 2 \\
\hline & & $\begin{array}{l}\text { Seleção recursos educacionais digitais para o Ensino de } \\
\text { Matemática }\end{array}$ & 2 \\
\hline & & Uso das TIC na Formação de Professores à Distância & 1 \\
\hline & & Uso das TIC na prática do professor de matemática & 1 \\
\hline & & Uso das TIC no ensino da álgebra na Educação Básica & 1 \\
\hline & & Uso das TIC no Ensino de Matemática & 1 \\
\hline & & Uso das TIC no ensino e aprendizagem de Cálculo & 1 \\
\hline & & Uso das TIC no ensino e aprendizagem de Geometria & 1 \\
\hline & & Uso do vídeo como recurso didático & 1 \\
\hline \multirow{4}{*}{$\begin{array}{l}\text { Estudos sobre a História } \\
\text { da Educação Matemática }\end{array}$} & \multirow{4}{*}{16} & $\begin{array}{l}\text { Análise histórica de documentos norteadores para a } \\
\text { Educação com foco no ensino de matemática }\end{array}$ & 1 \\
\hline & & $\begin{array}{l}\text { Análise histórica de material didático no ensino de } \\
\text { matemática }\end{array}$ & 4 \\
\hline & & $\begin{array}{l}\text { História da disciplina de Desenho na formação de } \\
\text { professores }\end{array}$ & 1 \\
\hline & & História da disciplina de História da Matemática na & 1 \\
\hline
\end{tabular}

Revista de investigação e divulgação em Educação Matemática, Juiz de Fora, v. 4, n. 1, p. 1-25, jan./dez. 2020. 


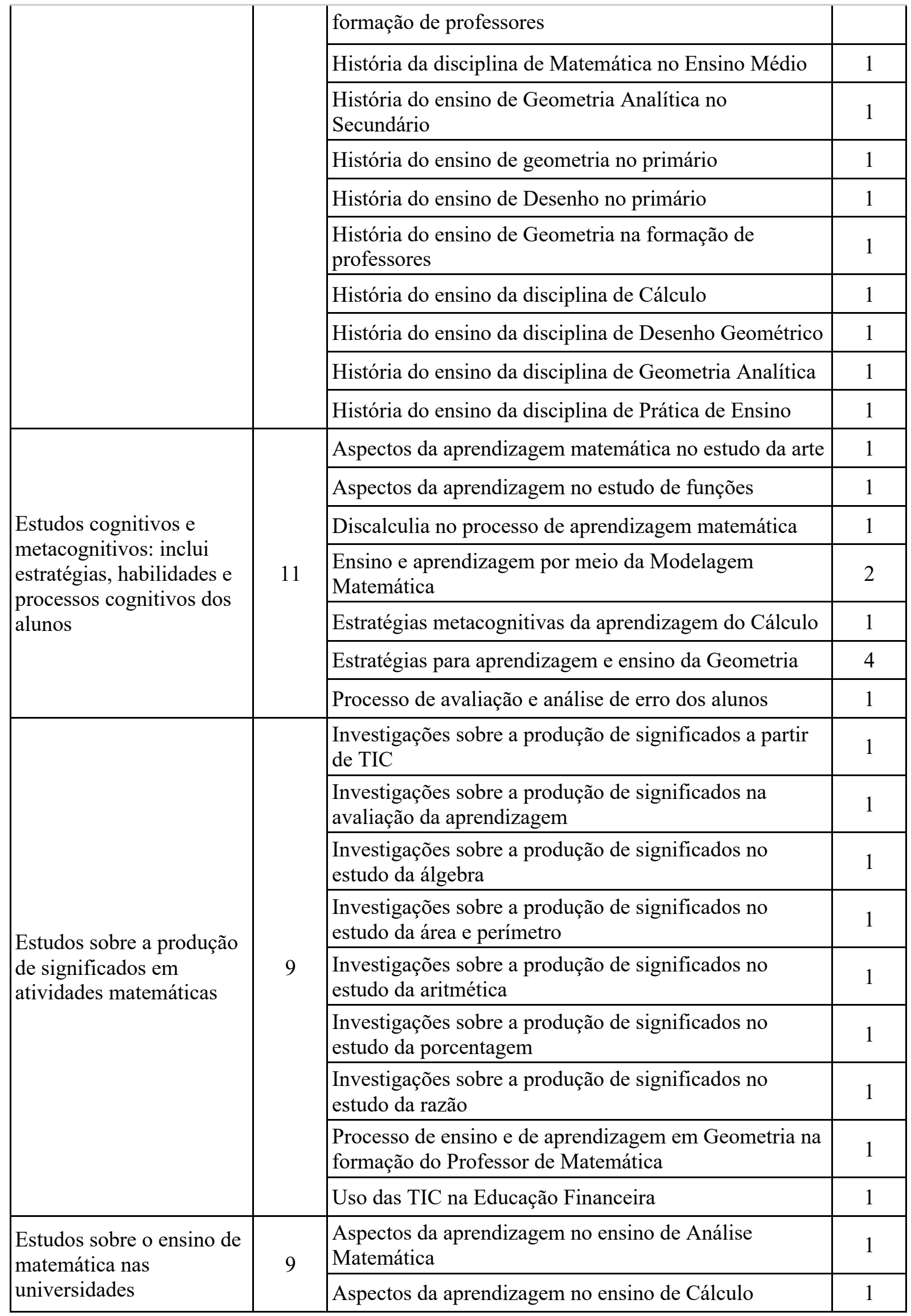

Revista de investigação e divulgação em Educação Matemática, Juiz de Fora, v. 4, n. 1, p. 1-25, jan./dez. 2020. 


\begin{tabular}{|c|c|c|c|}
\hline & & $\begin{array}{l}\text { Aspectos da aprendizagem no ensino de Geometria } \\
\text { Analítica }\end{array}$ & 1 \\
\hline & & $\begin{array}{l}\text { Aspectos epistemológicos, desenvolvimento conceitual, } \\
\text { habilidades cognitivas }\end{array}$ & 1 \\
\hline & & $\begin{array}{l}\text { Concepção, reflexão, ensino e aprendizagem de números } \\
\text { reais e análise real }\end{array}$ & 1 \\
\hline & & $\begin{array}{l}\text { Estratégias metodológicas para a disciplina de Álgebra } \\
\text { Linear }\end{array}$ & 2 \\
\hline & & $\begin{array}{l}\text { Estratégias metodológicas para redução do percentual de } \\
\text { reprovação na disciplina de Cálculo }\end{array}$ & 1 \\
\hline & & $\begin{array}{l}\text { Possibilidades e limitações da utilização da metodologia } \\
\text { de resolução de problemas no Ensino e Aprendizagem } \\
\text { da Matemática }\end{array}$ & 1 \\
\hline \multirow{4}{*}{$\begin{array}{l}\text { Estudos sobre Educação } \\
\text { Estatística }\end{array}$} & \multirow{4}{*}{5} & Aspectos da aprendizagem no estudo da Estatística & 1 \\
\hline & & $\begin{array}{l}\text { Ensino e aprendizagem da Estatística no contexto da } \\
\text { Educação à Distância }\end{array}$ & 1 \\
\hline & & Estratégias para o ensino e aprendizagem da Estatística & 2 \\
\hline & & $\begin{array}{l}\text { Educação Financeira sob aspectos da Educação } \\
\text { Estatística }\end{array}$ & 1 \\
\hline \multirow{3}{*}{$\begin{array}{l}\text { Estudos sobre o Professor } \\
\text { de Matemática: } \\
\text { (Caracterização, ideário, } \\
\text { saberes; formação } \\
\text { continuada; prática e } \\
\text { desenvolvimento } \\
\text { profissional; história.) }\end{array}$} & \multirow{3}{*}{4} & $\begin{array}{l}\text { Formação continuada de professores de matemática e o } \\
\text { conceito de infinito }\end{array}$ & 1 \\
\hline & & Prática docente em situações didáticas & 1 \\
\hline & & Processo de avaliação e análise de erro dos alunos & 2 \\
\hline \multirow{4}{*}{$\begin{array}{l}\text { Estudos sobre Educação } \\
\text { de Jovens e Adultos }\end{array}$} & \multirow{4}{*}{4} & $\begin{array}{l}\text { Produção de significado no estudo da Matemática } \\
\text { Financeira }\end{array}$ & 1 \\
\hline & & Análise de situações didáticas da prática pedagógica & 1 \\
\hline & & Estratégias para aprendizagem e ensino da Geometria & 1 \\
\hline & & $\begin{array}{l}\text { Ensino e aprendizagem da Matemática Financeira por } \\
\text { meio de recursos tecnológicos }\end{array}$ & 1 \\
\hline \multirow{4}{*}{$\begin{array}{l}\text { Estudos sobre a } \\
\text { matemática no contexto da } \\
\text { Educação } \\
\text { Inclusiva/Educação } \\
\text { Especial }\end{array}$} & \multirow{4}{*}{4} & Aprendizagem matemática sob a perspectiva do autismo & 1 \\
\hline & & Divisão por alunos surdos & 1 \\
\hline & & $\begin{array}{l}\text { Produção de significado no estudo da Matemática } \\
\text { Financeira }\end{array}$ & 1 \\
\hline & & Inclusão de alunos surdos nas aulas de matemática & 1 \\
\hline \multirow{4}{*}{$\begin{array}{l}\text { Estudos sobre a formação } \\
\text { de Professores de } \\
\text { Matemática }\end{array}$} & \multirow{4}{*}{4} & $\begin{array}{l}\text { Características, crenças, concepções, discurso sobre a } \\
\text { prática }\end{array}$ & 1 \\
\hline & & Tecnologias no ensino e aprendizagem de Geometria & 1 \\
\hline & & $\begin{array}{l}\text { Ensino de Geometria na formação de professores dos } \\
\text { Anos Iniciais do Ensino Fundamental }\end{array}$ & 1 \\
\hline & & $\begin{array}{l}\text { Estratégias para aprendizagem e ensino da Geometria } \\
\text { Projetiva }\end{array}$ & 1 \\
\hline
\end{tabular}

Revista de investigação e divulgação em Educação Matemática, Juiz de Fora, v. 4, n. 1, p. 1-25, jan./dez. 2020. 


\begin{tabular}{|c|c|c|c|}
\hline \multirow{2}{*}{$\begin{array}{l}\text { Estudos sobre ambientes } \\
\text { colaborativos de } \\
\text { aprendizagem }\end{array}$} & \multirow[b]{2}{*}{3} & Sala de aula invertida como metodologia de ensino & 1 \\
\hline & & $\begin{array}{l}\text { Ensino e aprendizagem da Geometria por meio de } \\
\text { recursos tecnológicos }\end{array}$ & 2 \\
\hline \multirow{2}{*}{$\begin{array}{l}\text { Estudos sobre a } \\
\text { Modelagem Matemática } \\
\text { como metodologia de } \\
\text { ensino }\end{array}$} & \multirow{2}{*}{2} & $\begin{array}{l}\text { Estudo de funções na Educação Básica sob a perspectiva } \\
\text { da Modelagem Matemática }\end{array}$ & 1 \\
\hline & & \begin{tabular}{|l|} 
Formação continuada de professores de matemática e \\
Modelagem Matemática
\end{tabular} & 1 \\
\hline \multirow{2}{*}{$\begin{array}{l}\text { Estudos sobre avaliações e } \\
\text { avaliações em larga escala }\end{array}$} & \multirow[b]{2}{*}{2} & Interpretação de resultados de avaliações em larga escala & 1 \\
\hline & & \begin{tabular}{|l|} 
Aspectos didáticos nas questões de avaliação \\
matemática
\end{tabular} & 1 \\
\hline \multirow{2}{*}{$\begin{array}{l}\text { Estudos sobre Educação a } \\
\text { Distância }\end{array}$} & \multirow{2}{*}{2} & $\begin{array}{l}\text { Formação de tutores para o Ensino de Matemática na } \\
\text { Educação Básica }\end{array}$ & 1 \\
\hline & & $\begin{array}{l}\text { Aspetos da aprendizagem na disciplina de Álgebra } \\
\text { Linear }\end{array}$ & 1 \\
\hline \multirow{2}{*}{$\begin{array}{l}\text { Estudos sobre o currículo } \\
\text { de matemática na } \\
\text { Educação Básica }\end{array}$} & \multirow[b]{2}{*}{2} & Estratégias para aprendizagem e ensino da Geometria & 1 \\
\hline & & $\begin{array}{l}\text { Estratégias para aprendizagem e ensino da Geometria } \\
\text { Projetiva no Ensino Básico }\end{array}$ & 1 \\
\hline Estudos Interdisciplinares & 1 & $\begin{array}{l}\text { Aprendizagem de matemática e física sob aspectos } \\
\text { interdisciplinares }\end{array}$ & 1 \\
\hline $\begin{array}{l}\text { Estudos sobre Objetos de } \\
\text { Aprendizagem }\end{array}$ & 1 & Objetos de Aprendizagem para a Educação Financeira & 1 \\
\hline $\begin{array}{l}\text { Estudos sobre recursos } \\
\text { didáticos para o ensino da } \\
\text { matemática }\end{array}$ & 1 & $\begin{array}{l}\text { Análise de manuais de ensino relacionados à } \\
\text { proporcionalidade }\end{array}$ & 1 \\
\hline TOTAL & 123 & TOTAL & 123 \\
\hline
\end{tabular}

Fonte: dados da pesquisa.

A distribuição dos trabalhos classificados em focos e subfocos temáticos levou em consideração o tema geral da pesquisa, que geralmente era identificado no título e/ou no resumo e o subfoco foi identificado por meio do resumo e na maioria das vezes pelo referencial teórico descrito no trabalho. Em Fiorentini (2002) é possível observar focos temáticos que facilmente foram identificados dentre os 123 trabalhos, mas certamente houve a necessidade de se criar focos e subfocos específicos de acordo com o andamento do processo de fichamento e agrupamento das pesquisas.

A partir do Quadro 4 pode-se identificar as diferentes formas que a pesquisa em Educação Matemática se manifesta, mostrando uma diversidade saudável e pertinente, ressaltando as diferentes teorias utilizadas para a investigação dos distintos processos envolvidos no ensino e na aprendizagem da matemática.

Pela observação do Quadro 4, podemos destacar 19 focos temáticos e 90 subfocos

Revista de investigação e divulgação em Educação Matemática, Juiz de Fora, v. 4, n. 1, p. 1-25, jan./dez. 2020. 
temáticos. Alguns subfocos podem ser pertinentes a mais de um foco temático, mas para melhor visualização das categorias, a preferência foi mantê-las disjuntas assim como em Fiorentini (2002).

Os seis focos temáticos mais frequentes foram:

Estudos sobre Educação Financeira - 25 trabalhos (20\%)

Estudos das TIC na Educação Matemática - 18 trabalhos (15\%)

Estudos sobre a História da Educação Matemática - 16 trabalhos (13\%)

Estudos cognitivos e metacognitivos: inclui estratégias, habilidades e processos cognitivos dos alunos -11 trabalhos $-(9 \%)$

Estudos sobre a produção de significados em atividades matemáticas - 9 trabalhos (7\%)

Estudos sobre o ensino de matemática nas universidades - 9 trabalhos (7\%)

A partir do Quadro 4 e deste pequeno resumo, podemos observar que somente esses 6 focos já representam mais de $70 \%$ dos trabalhos apurados no período em questão. Dentre esses seis focos apenas 1 é referente à linha de pesquisa 2 do Programa: TIC na Educação Matemática. Esse foco apresenta o segundo maior número de trabalhos relacionados. Apesar de ser ressaltada essa característica, é necessário dizer que nem todos os trabalhos agrupados sob o tema "TIC na Educação Matemática” foram orientados por professores da linha de pesquisa 2. Antes de obtermos uma avaliação final do quadro temático da pesquisa feita no PPGEM, dada a grande concentração de docentes que atuam na linha de pesquisa 1, isso poderia influenciar a temática abrangente no programa, dado que mais investigações são promovidas dentro dessa linha de pesquisa. Além disso, como pôde ser observado no quadro de focos e subfocos temáticos, há subfocos da linha de pesquisa 1 que tratam de temas que estão relacionados com a linha de pesquisa 2 e vice-versa. O que nos leva a considerar que há uma interseção entre as duas linhas de pesquisa e questionar a necessidade da existência de ambas, já que alguns professores atuam, em termos de focos de investigação, nas duas linhas de pesquisa. 


\section{Tendências Temáticas dos Produtos Educacionais}

Diferentemente da análise temática feita das dissertações, para os Produtos Educacionais a identificação e o agrupamento foram realizados por meio do tipo de PE desenvolvido. Uma vez que a temática da dissertação influencia também o PE, decidiu-se que em relação à produção de recursos para a utilização de professores e alunos no âmbito do ensino e da aprendizagem da matemática seria mais interessante caracterizar os tipos de produtos constituídos. Se é um produto digital ou se é um produto físico, se é voltado para o professor ou para o aluno, se é uma atividade ou se é um artigo etc.

Inicialmente foi feito um levantamento do total de PE disponíveis no site do PPGEM. Os arquivos foram baixados e separados por ano de publicação. A seguir, no Quadro 5, está o quantitativo de PE apresentados no PPGEM no período de 2009 e 2019.

Quadro 5 - Quantitativo de Produtos Educacionais apresentados entre 2009 e 2019 no PPGEM

\begin{tabular}{|c|c|}
\hline Ano & $\begin{array}{c}\mathbf{N}^{0} \text { de Produtos Educacionais oriundos } \\
\text { das Dissertações defendidas }\end{array}$ \\
\hline 2009 & 0 \\
\hline 2010 & 0 \\
\hline 2011 & 10 \\
\hline 2012 & 10 \\
\hline 2013 & 17 \\
\hline 2014 & 9 \\
\hline 2015 & 16 \\
\hline 2016 & 12 \\
\hline 2017 & 20 \\
\hline 2018 & 16 \\
\hline 2019 & 11 \\
\hline Total & 121 \\
\hline
\end{tabular}

Fonte: dados da pesquisa.

Foi necessário exibir um quadro com as quantidades de PE apresentados pois, em alguns 
anos, percebeu-se que há quantidades diferentes de produtos apresentados e dissertações defendidas. Isso se deve ao fato de que 3 alunos produziram mais de um PE, 2 no ano de 2017 e 1 no ano de 2018. Além disso, de acordo com as informações da secretaria do Programa, há 6 PE que não estão disponíveis no site do PPGEM, 3 no ano de 2011, 1 no ano de 2012, 1 no ano de 2013, 1 do ano de 2016. Este referente ao ano de 2016 foi enviado por e-mail para as autoras da pesquisa.

Os mesmos cuidados em relação ao fichamento das dissertações foram tomados para os PE. Com base nos parâmetros que podem ser encontrados no guia de Considerações sobre classificação de Produção Técnica da CAPES (BRASIL, 2016), resolveu-se identificar os produtos de acordo com as seguintes categorias: natureza (oficina, livro, tarefa...); público alvo (professor, aluno...); digital (online) /físico (impresso); disponibiliza manual /instruções; acesso livre (online); nível de ensino (escolaridade); modalidade de ensino (regular, EJA, EAD, educação especial...) e o conteúdo disciplinar. Essas categorias foram estipuladas e adaptadas de acordo com o conteúdo e apresentação dos PE do PPGEM. Todos os dados coletados foram organizados em planilhas eletrônicas.

Para a identificação de cada uma das categorias, foi feita a leitura dos títulos dos produtos e da apresentação dos mesmos ou do resumo, quando havia. Em alguns trabalhos foi necessária uma leitura integral do Produto por não ser possível a identificação dessas características apenas com a leitura da apresentação.

O Quadro 6 resume o levantamento em relação à natureza dos produtos.

Quadro 6 - Natureza dos Produtos Educacionais apresentados entre 2009 e 2019 no PPGEM

\begin{tabular}{|c|c|c|}
\hline $\mathbf{N}^{\mathbf{0}}$ & NATUREZA & Quant. \\
\hline 1 & Atividades & 25 \\
\hline 2 & Tarefas & 21 \\
\hline 3 & Texto & 15 \\
\hline 4 & Artigo Científico & 11 \\
\hline 5 & Minicurso & 4 \\
\hline 6 & Curso de Formação Continuada & 3 \\
\hline 7 & Curso de Serviço & 3 \\
\hline 8 & Manual & 3 \\
\hline 9 & Aplicativo & 2 \\
\hline
\end{tabular}




\begin{tabular}{|c|c|c|}
\hline 10 & Curso de Extensão & 2 \\
\hline 11 & Livreto & 2 \\
\hline 12 & Oficina & 2 \\
\hline 13 & Processo de implementação de metodologia & 2 \\
\hline 14 & Relato de Experiência & 2 \\
\hline 15 & Relatório Técnico & 2 \\
\hline 16 & WebSite & 1 \\
\hline 17 & Atividades Investigativas e Exploratórias & 1 \\
\hline 18 & Atividades Online & 1 \\
\hline 19 & Caderno de Atividades & 1 \\
\hline 20 & Catálogo & 1 \\
\hline 21 & Curso Lato Sensu & 1 \\
\hline 22 & Entrevista & 1 \\
\hline 23 & Fichamento & 1 \\
\hline 24 & Folheto Informativo & 1 \\
\hline 25 & Guia & 1 \\
\hline 26 & Guia para atividades & 1 \\
\hline 27 & Mecanismo de Busca & 1 \\
\hline 28 & Mecanismo de seleção de vídeos & 1 \\
\hline 29 & Metodologia de Pesquisa & 1 \\
\hline 30 & Proposta de Curso & 1 \\
\hline 31 & Proposta de Jogos & 1 \\
\hline 32 & Proposta de plano de aula & 1 \\
\hline 33 & Proposta de um Curso Online & 1 \\
\hline 34 & Proposta para o desenvolvimento de disciplinas de Matemática & 1 \\
\hline 35 & Resenha de filmes & 1 \\
\hline 36 & Software/Atividades & 1 \\
\hline 37 & Vídeos & 1 \\
\hline \multicolumn{2}{|r|}{ Total } & 121 \\
\hline
\end{tabular}

Fonte: dados da pesquisa.

Pelo menos 10 produtos não apresentam informações claras a respeito da sua finalidade. Por isso, esses trabalhos necessitaram de uma leitura completa de seu conteúdo com intuito de identificar a sua finalidade. A importância de esclarecer a finalidade de um PE é fundamental 
para que o leitor/usuário entenda a intenção do autor na utilização de sua produção.

Foram identificadas 37 naturezas diferentes entre os PE, dentre elas 4 se destacam por apresentar mais de 10 produtos relacionados. Juntas, essas 4 classificações representam quase 59\% dos Produtos:

Atividades - 25 trabalhos (21\%);

Tarefas - 21 trabalhos (17\%);

Texto - 15 trabalhos (12\%);

Artigo Científico - 11 trabalhos (9\%).

Em relação ao público-alvo dos $\mathrm{PE}, 45 \%$ se destinam aos alunos, 44\% aos professores e $11 \%$ não apresentam de forma clara a qual público se destina. Essa análise considerou a quem o produto "final" era destinado. Por exemplo, quando não havia claramente a informação de qual seria o público-alvo, num produto que apresenta atividades para aplicar com os alunos, mesmo tendo um manual para o professor, era identificado o público-alvo como o aluno.

Já em relação ao Produto, se poderia ser impresso ou era acessado somente por meio digital, pôde-se identificar que $81 \%$ dos produtos podem ser impressos, uma vez que forem acessados os arquivos PDF no site do PPGEM. Apenas 9\% dos Produtos devem ser utilizados com auxílio de uma plataforma digital, por serem softwares, aplicativos, vídeos, etc., na plataforma apenas consta um manual de utilização ou guia. Além disso, os outros $10 \%$ se dividem em parte que poderia ser impressa e outra parte digital, ou seja, para serem utilizados esses produtos requerem além de um material em PDF que contém, por exemplo, enunciados de atividades, também é necessário o auxílio de algum programa, software, vídeo, aplicativo, etc.

Muitos Produtos são intuitivos de serem utilizados, mas mesmo assim, é indispensável que seja disponibilizado algum tipo de manual para guiar o usuário na sua experiência com cada Produto. Foi identificado que $72 \%$ dos Produtos apresentam algum tipo de manual que explica seus objetivos, como utilizá-lo e suas funcionalidades. Dentro dos outros $28 \%$ há Produtos que são apresentados em forma de texto ou artigos científicos que talvez, para os autores, não seria necessário incluir tal recurso.

Um outro aspecto muito importante é a acessibilidade destes Produtos. Como a maioria pode ser acessada pela página do PPGEM, quase todos podem ser obtidos de forma completa, 
incluindo textos, aplicativos, softwares e páginas na web. Há apenas um dos 121 Produtos disponibilizados que não apresenta acesso livre para o recurso digital que foi desenvolvido. $\mathrm{O}$ link disponibilizado no texto que descreve o recurso não permite acesso a ferramenta, fazendo com que parte do trabalho não possa ser acessada pelo usuário.

Outra característica muito importante a ser analisada a respeito dos Produtos é o nível de ensino a que são destinados. A classificação obedeceu ao nível ao qual o produto final era destinado. Se era uma tarefa para alunos do Ensino Médio, se era um curso de extensão para alunos do Ensino Superior etc. A seguir, o Quadro 7 expressa a classificação do PE de acordo com o nível de ensino:

Quadro 7 - Níveis de Ensino dos Produtos Educacionais apresentados entre 2009 e 2019 no PPGEM

\begin{tabular}{|c|c|}
\hline Nível de Ensino & Quant. \\
\hline $\begin{array}{c}\text { Anos Iniciais do Ensino } \\
\text { Fundamental }\end{array}$ & 5 \\
\hline $\begin{array}{c}\text { Anos Finais do Ensino } \\
\text { Fundamental }\end{array}$ & 22 \\
\hline $\begin{array}{c}\text { Anos Finais do Ensino } \\
\text { Fundamental e Ensino Médio }\end{array}$ & 3 \\
\hline Ensino Médio & 16 \\
\hline Educação Básica & 8 \\
\hline Ensino Superior & 21 \\
\hline Fundamental, Médio e Superior & 1 \\
\hline Não identificado/especificado & 45 \\
\hline Total & 121 \\
\hline
\end{tabular}

Fonte: dados da pesquisa.

De acordo com o Quadro 7, 45 Produtos (37\%) não especificaram a qual nível de ensino era destinado ou não se pôde identificar. Dentro desse número, há ainda os Produtos que foram classificados quanto à natureza como textos e artigos, que em sua maioria, eram direcionados a professores e público em geral, assim talvez sendo considerada a não necessidade de fazer esse tipo de especificação. Dos que puderam ser identificados, mais de $70 \%$ dos Produtos são focados na Educação Básica e desses, apenas 6\% destina-se aos Anos Iniciais do Ensino Fundamental.

Algo importante a ser destacado para essa categoria é que, apesar de haver uma separação de Ensino Médio e Ensino Fundamental, uma vez que essas classificações poderiam 
ser englobadas pela classificação da Educação Básica, as autoras decidiram manter essa separação respeitando a especificidade que cada Produto Educacional estipula como públicoalvo. Há Produtos em que o conteúdo e toda a metodologia foi constituída para ser aplicado no Ensino Fundamental e outros cujo o conteúdo e os aspectos metodológicos podem ser adaptados para toda Educação Básica, por exemplo. Dessa forma, preferiu-se manter a distinção entre essas classificações nessa categoria a fim de preservar os dados obtidos e assim observar, por exemplo, a baixa quantidade de Produtos destinados aos anos iniciais e propor discussões a respeito das razões de isso acontecer no PPGEM.

Seguindo a linha de classificação do público para o qual se destina no âmbito educacional, a classificação em relação às modalidades de ensino é necessária a fim de se perceber a preocupação que cada modalidade tem recebido de acordo com a produção de recursos educacionais e os possíveis desdobramentos desse aspecto. A partir do Quadro 8, podese perceber que 50\% do Produtos são destinados à modalidade de ensino regular e os demais se distribuem entre as modalidades de Ensino à Distância (6\%), Educação de Jovens e Adultos (4\%), Educação Especial (3\%) e os que não especificaram ou não puderam ser identificados $(37 \%)$.

Quadro 8 - Modalidades de Ensino dos Produtos Educacionais apresentados entre 2009 e 2019 no PPGEM

\begin{tabular}{|c|c|}
\hline Modalidade de Ensino & Quant. \\
\hline Regular & 60 \\
\hline EAD & 7 \\
\hline EJA & 5 \\
\hline Educação Especial & 4 \\
\hline Não identificado/especificado & 45 \\
\hline Total & 121 \\
\hline
\end{tabular}

Fonte: dados da pesquisa.

Só ficava claro que a modalidade não era regular quando o PE enfatizava que era para alunos com necessidades educativas especiais, alunos da EJA ou alunos da educação à distância. Nos demais casos não estava explícita a modalidade de ensino a que se destina o PE. A importância de se destacar essas características, tanto em relação ao nível de ensino quanto à modalidade, é que ajuda o usuário a entender e a utilizar o Produto de acordo com as intenções 
dos autores. Quanto mais informação sobre o PE estiver disponível mais adequadamente ele será utilizado e implementado pelos usuários.

A última característica dos PE analisada foi qual/quais conteúdo (s) disciplinares eram tratados nos trabalhos. Foram identificados 31 diferentes conteúdos que podem ser observados no Quadro 9.

Quadro 9 - Conteúdos Disciplinares dos Produtos Educacionais apresentados entre 2009 e 2019 no

PPGEM

\begin{tabular}{|c|c|c|}
\hline $\mathbf{N}^{\mathbf{o}}$ & Conteúdo Disciplinar & Quant. \\
\hline 1 & Educação Financeira & 28 \\
\hline 2 & Geometria & 15 \\
\hline 3 & Tecnologias da Informação e Comunicação & 14 \\
\hline 4 & História da Educação Matemática & 10 \\
\hline 5 & Educação Estatística & 4 \\
\hline 6 & Funções & 4 \\
\hline 7 & Avaliação & 3 \\
\hline 8 & Cálculo Diferencial e Integral & 3 \\
\hline 9 & Matemática Financeira & 2 \\
\hline 10 & Álgebra & 2 \\
\hline 11 & Álgebra Linear & 2 \\
\hline 12 & Geometria Analítica & 2 \\
\hline 13 & Modelagem Matemática & 2 \\
\hline 14 & Geometria Projetiva & 2 \\
\hline 15 & TIC/Educação Financeira & 1 \\
\hline 16 & Análise & 1 \\
\hline 17 & Análise Combinatória & 1 \\
\hline 18 & Aritmética & 1 \\
\hline 19 & Aritmética e Raciocínio Lógico & 1 \\
\hline 20 & Divisão & 1 \\
\hline 21 & Educação Empreendedora/Educação Financeira/TIC & 1 \\
\hline 22 & Educação Financeira/ Educação Estatística & 1 \\
\hline 23 & Ensino de Matemática & 1 \\
\hline 24 & Funções e Energia & 1 \\
\hline
\end{tabular}

Revista de investigação e divulgação em Educação Matemática, Juiz de Fora, v. 4, n. 1, p. 1-25, jan./dez. 2020. 


\begin{tabular}{|c|c|c|}
\hline 25 & Geometria das Transformações & 1 \\
\hline 26 & Geometria, Coordenação Motora, Raciocínio Lógico & 1 \\
\hline 27 & Geometria, razão e proporção, unidades de comprimento & 1 \\
\hline 28 & Matemática e Arte & 1 \\
\hline 29 & Números Reais & 1 \\
\hline 30 & Porcentagem & 1 \\
\hline 31 & Razão e Proporção & 1 \\
\hline 32 & Não identificado/especificado & 11 \\
\hline & Total & 121 \\
\hline
\end{tabular}

Fonte: dados da pesquisa.

Os trabalhos em que não puderam ser identificados ou não foram especificados os conteúdos se tratavam de relatórios técnicos, mecanismo de busca, aplicativos, textos, artigos, entrevista, manuais que falavam a respeito de metodologias, processos e que não tratavam de um conteúdo disciplinar específico.

É importante ressaltar que mais da metade dos Produtos (55\%) se concentram em apenas 4 conteúdos disciplinares diferentes: Educação Financeira (23\%), Geometria (12\%), Tecnologias da Informação e Comunicação (12\%) e História da Educação Matemática (8\%). Essa tendência é um reflexo do que se concluiu anteriormente em relação aos principais temas das dissertações. Como o PE está relacionado diretamente com a pesquisa desenvolvida na dissertação, o tema influencia o conteúdo que é abordado no Produto.

Todos os aspectos que foram destacados a respeito dos PE são relevantes e influenciam na seleção e escolha do usuário do recurso mais adequado para as suas necessidades. Além disso, Produtos sistematizados caracterizam o Programa em relação aos tipos de Produtos que estão sendo produzidos, a quem estão sendo direcionados, os conteúdos e como podem ser acessados. Deixar claro todas as informações a respeito de um PE como a finalidade, qual o público-alvo, qual nível/modalidade de ensino, conteúdo, bem como outras características que o autor achar importante descrever é fundamental para que o usuário entenda o Produto e possa utilizá-lo. Ademais, esse tipo de descrição contribui para pesquisas de levantamento de dados sobre a produção de PE, tal como esse trabalho, no sentido de analisar esses recursos a fim de caracterizar o desenvolvimento de investigações em Mestrados Profissionais. 


\section{Considerações Finais}

O mapeamento temático das 123 dissertações defendidas do PPGEM, revelou o predomínio de investigações desenvolvidas seguindo a linha 1 de pesquisa que tem como tema o "Ensino e Aprendizagem da Matemática, Análise dos condicionantes da sala de aula e Intervenção Pedagógica em Matemática”. Os temas predominantes identificados por meio das palavras-chave frequentes e dos temas gerais dos trabalhos revelou uma forte concentração da pesquisa em torno de 3 principais temas: Educação Financeira, História da Educação Matemática e Tecnologias da Informação e Comunicação na Educação Matemática.

Em relação ao mapeamento dos PE foi constatado que a predominância são trabalhos com foco nos mesmos temas que as dissertações, salvo um destaque em relação aos trabalhos que apresentam conteúdos da Geometria. Além disso, a partir do fichamento realizado e de todas as características analisadas mencionadas na seção anterior, verificou-se que há uma tendência dos Produtos serem apresentados na forma de atividades e tarefas, que não se restringem a recursos digitais. Foi mencionado também que, em relação ao público-alvo, os Produtos se dividem igualmente destinados tanto a professores como a alunos.

Em relação à confecção de um manual de auxílio e orientação na utilização do Produto, a maioria dos autores demonstraram preocupação, entendendo a importância de informar os usuários os objetivos e finalidades do recurso.

Há também uma concentração dos Produtos em relação ao nível de ensino, priorizando os anos finais do Ensino Fundamental e o Médio, sendo que a metade dos Produtos são para a modalidade de ensino regular. Esses dados poderiam ter sido mais expressivos, ou seja, descreverem melhor a realidade dos aspectos analisados se não houvessem trabalhos em que não foi possível identificar alguns itens de acordo com os dados apresentados na seção anterior.

Os resultados obtidos a partir desse mapeamento, demonstraram uma coerência entre os temas que mais se destacaram e as linhas de pesquisa do Programa. Observou-se também que claramente uma linha de pesquisa apresenta mais vantagens em publicações de trabalhos dado a grande maioria dos docentes pertencerem a essa linha. Todos os temas identificados estão de acordo com as especificidades encontradas em cada linha de pesquisa. Foi observado também que há professores que atuam em ambas linhas de pesquisa, havendo dessa forma, uma interseção de investigações entre as linhas de pesquisa 1 e 2.

De maneira geral, o perfil da pesquisa no PPGEM se inclina mais para as áreas que 
relacionam temas como Educação Financeira, História da Educação Matemática e TIC na Educação Matemática. A partir dos dados obtidos desse levantamento, há possíveis desdobramentos que podem ser investigados em relação à caracterização da pesquisa no PPGEM, da importância da sistematização de PE, das metodologias e dos suportes teóricos mais frequentemente utilizados pelos autores, do perfil do público que tem sido atraído para o Programa, bem como o impacto desses trabalhos na vida pessoal e profissional dos egressos.

\section{Referências}

BRASIL. Considerações sobre Classificação de Produção Técnica: ensino. Ministério da Educação. Coordenação de Aperfeiçoamento de Pessoal de Nível Superior. Brasília, 2016.

BRASIL, Coordenação de Aperfeiçoamento de Pessoal de Nível Superior. Documento de Área - Ensino, Brasília, 2019.

CARVALHO, J. B. P. F. O que é educação matemática. Temas e Debates, Rio Claro, SP, v. 4, n.3, p. 17-26, 1991.

D’AMBROSIO, U. Educação Matemática da teoria à prática. Campinas: Papirus, 1996.

FIORENTINI, D. Mapeamento e balanço dos trabalhos do GT-19 (Educação Matemática) no período de 1998 a 2001. Reunião Anual da ANPEd, 25., 2005, Caxambú, MG. Anais... Caxambú, MG: [s.n.], 2002, p. 1-17.

MASSI, L.; CARVALHO, H.; GIORDAN, M. Perfil Socioformativo dos Orientadores, Heterogeneidade e Hierarquia Social na área de Ensino da Capes. Investigações em Ensino de Ciências (Online), v. 25, p. 421-432, 2020. 